\title{
Credit Risk and Local Government Bonds: A Case from China
}

\author{
Jiguang Wang ${ }^{*}$, Jingfeng Li \\ School of Economics and Management, Shanxi University, Taiyuan, China \\ *Corresponding author: wangjg@sxu.edu.cn
}

Received March 10, 2014; Revised March 28, 2014; Accepted April 01, 2014

\begin{abstract}
Issuing local government bonds will become a main financing manner and channel of municipal infrastructure in China while its major problem is volumes and credit risk control. Based on the KMV model, the credit risk model for municipal bonds is constructed in this paper and further study the patterns its probability distribution to improve prediction accuracy. After determining the forecast standards, we compute the safe issue volume of those provinces and municipalities who had issued municipal bonds. The end is a brief analysis of the reason to its bad marketing.
\end{abstract}

Keywords: local government bonds; KMV model; credit risk; safe issue volume

Cite This Article: Jiguang Wang, and Jingfeng Li, "Credit Risk and Local Government Bonds: A Case from China.” Journal of Finance and Economics, vol. 2, no. 4 (2014): 113-117. doi: 10.12691/jfe-2-4-2.

\section{Introduction}

It's the imbalance between financial power and routine power of local government after the System of Tax Distribution in 1994 that seriously restricted China Local's development. In fact, the local government is supposed to play an important role under the Public Finance System which exacerbated the contradiction between insufficient financial resources and the local government's growing demand for local public construction funds. So, because of the current Budget Law that the local government is not allowed to budget deficit or to borrow directly, they raised numerous funds through various financing platform to make up the continued expanding funding gap. Up to the end of June 2010, the local government loans under the various financing platform reached $¥ 7.66$ trillion and the debt ratio has far exceeded $100 \%$ in which $23 \%$ is problem loans. Solving the huge local debt and preventing the emergence of "China's Subprime Crisis" is an urgent task in present.

In the cases of United States, Japan, Britain, France and other developed countries, they have rich experience in issuing and managing local government bond (Downing, Zhang, 2004). Illustrated by the case of the United States, its scale of local government bond (it named Municipal Bond in United States) has reached \$2.7 trillion at the end of 2008 from $\$ 859.5$ billion in 1985 which played a pivotal role in the cities or local areas of infrastructure construction. The issue of local government bond will be the final choice of the local government. The good news is China has started to explore the feasibility of local governments to issue bonds.

At the $18^{\text {th }}$ Session of the $11^{\text {th }}$ Committee of National People's Congress on Feb17, 2009, local government was approved to issue $¥ 200$ billion bond that the Ministry of Finance as the issuing agent which listed provincial budgets. But unfortunately, the investors do not welcome the local government bonds. Its price of the first local bond-XingJiang Bond-broke its par value in the first trading day and kept downturn continuously. In addition to this, the successive local bonds showed the same fate as XinJiang Bond that the subscription ratio decreased steadily in the primary market and kept "zero turnovers" in the secondary market consecutively. The result is that we have not anticipated yet.

Although the local government bonds is considered as Quasi-gilt-edged bonds in the West, the default events of New York City and Orange County proved that it has credit risk too. Especially under the financial crisis many analysts believe that the 2.7 trillion local government bond markets may be the next hardest hit area in the financial storm. Facts have proved that with the rapid development of China's capital market the investor possessed higher risk awareness correspondingly are very worried about its credit risk.

This paper will build a local government bonds credit risk prediction model based on the KMV by analyzing and testing its probability distribution form in order to improve the model's prediction accuracy.

\section{Literature Review}

There are rich experiences and theoretic studies of West countries in local government bonds. Mainly covers two areas.

The first area focused on local government bonds interest rates, insurance and other risk-related factors analysis. In early, Yawitz (1978) studied its risk premium based on the perspective of interest rate by analyzing the 
local government bond yields of United States from August 1965 to February 1973. Through a comprehensive analysis of New York City's financial crisis in the late 1970s, Kidwell and Trzcinka (1982) found that just the high interest rates local government bonds issued excessively is the major source of its crisis. McConnell and Picker (1993) maintained the local government bond default risk derived from the local government's debt level mainly and recommended to establish the national rather than the state-level bankruptcy court to service and improve its financial position of local government those at the verge of bankruptcy and protect investors ultimately after studied the issues related to the bankrupt local government caused by the debt crisis. Lately, Hong and Warga (2000) noted that the imperfect security trading system has increased its liquidity risk. Nanda and Singh (2004) have pointed out that the tax-free on local government bonds can result in the tax arbitrage effect that highlight its risk. So they proposed that matured bond insurance should be developed. So, Jordan (2012) have pointed out that the tax-free on local government bonds increased the risk of default. Schultz (2012), Leeper, Walker, Yang (2013) stated that lacking of necessary financial information disclosure system and strict system of independent audit which formed the risk. They believed that the insurance system of local government bonds is not a good way to resolve the default risk. Furthermore, Nguyen (2012) indicted that the high yield of local government bonds corresponded to its high default risk after analyzing the relationship between marginal tax rate and default risk of local government bond based on the option theory to explain the Muni Puzzle. Ang, Longstaff (2013) using a multifactor affine framework that allows for both systemic and sovereign-specific credit shocks, we find that there is much less systemic risk among U.S. sovereigns than among Eurozone sovereigns.

The other area focused on the risk measurement and calculation of local government bonds. As a classic, Black and Scholes (1973) constructed a research framework by taking equity right a call option as the originator of Credit Risk Quantitative Study so as to take shape the Merton Model (Merton 1973,1974)which applied to the area of credit risk on local government bonds gradually. To address the diffusion term structure, Jarrow, Lando, Turnbull (1997)designed a non-arbitrage Markov model (also named Jarrow-Turnbull Model) to study the credit risk by assessing the risk debt based the methods of random changed default probability of rating transformation matrix. And Shneyerov (2006) studied its price volatility and liquidity risk from the view of English Auction on the basis of Milgrom and Weber's (1982) the General Symmetric Model. Daniels, Diro Ejara, Vijayakumar (2010) analyzed the relationships between debt maturity, credit risk, and information asymmetry on municipal bonds using a system of equations approach. They find that under conditions of lower information asymmetry that prevails in the municipal sector, higher-rated bonds have longer maturities than low-rated bonds. This result differs from that observed in the corporate sector.

In addition, a number of institutions developed various credit risk measurement model. The popular quantitative credit risk measurement model such as KMV Co., Ltd's Credit Monitor Model (KMV, also named EDF). J.P.Morgan's Credit-VaR and Credit Metrics, Credit Suisse’s Credit Risk+, Mc Kinsey’s Credit Portfolio View and Neural Network Model, etc.

Han, et al., (2003, 2005) constructed the local government bond credit risk measurement model by substituting the asset value of KMV with local fiscal revenue. It idea can be expressed as the bond issuer-local government-transfer the tax right to the buyers and they can redeem it by Gensaki trading in the end. But if it outlined a fiscal deficit at the maturity date, the local government will default.

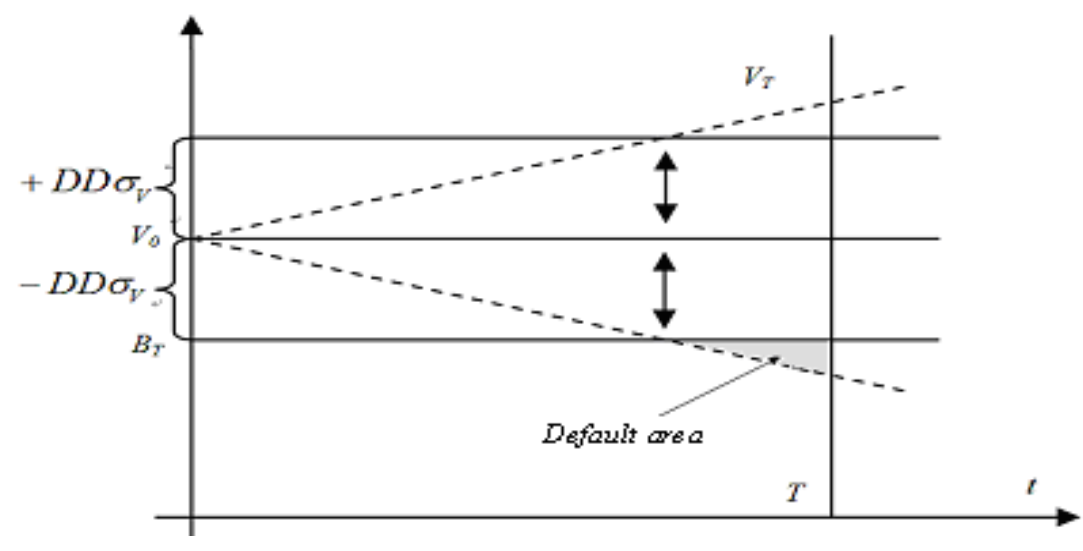

Figure 1. The diagram of the local government bond Credit risk measurement

Although each of these above risk models have their appropriated application area, the KMV is more suitable to our local government bonds credit risk study for it needn't much data and its characteristics of high sensitivity. So this paper will establish a local government bond credit risk model with the ideas of KMV.

This paper will discuss its risk and security issue volume of local government bonds quantitatively so as to strengthen risk perception based the optimized KMV model at the beginning of the establishment of China local government bonds market and guide it develop healthily.

\section{The Construction of Local Government Bond Credit Risk Measurement Model}

The local revenue can be the basis of issued bonds volume when assessing it credit risk. Whereas the local 
revenue is uncertain that could evolve credit risk in the same way. This uncertainty can be described by random process.

So, once the payable local revenue is less than the debt principal and interest, the local government will default. Therefore, describing the fluctuations of fiscal revenue is just the key in this study.

In general, the local revenues as the subject asset that is no direct relationship of local revenue between different years. It duly corresponds to the characteristics of random process. The payable local revenue $\boldsymbol{V}_{\boldsymbol{t}}$ can be expressed as:

$$
V_{t}=f\left(Z_{t}\right)
$$

Where $\boldsymbol{V}_{\boldsymbol{t}}$ is the payable local revenue after deducting the necessary expenses at $t$ time. We named it payable revenue later; $\boldsymbol{Z}_{\boldsymbol{t}}$ is a random variable; $f(\bullet)$ is a function to be determined.

When it goes to the maturity date $(t=T)$, if the payable revenue $V_{T}$ is less than the principal and interest of debt $B_{T}$, that is $V_{T}<B_{T}$, the local government default. $V_{T}=B_{T}$ is just the default point. Let $p$ denote the probability of default:

$$
\begin{aligned}
p & =P\left[V_{T}<B_{T}\right] \\
& =P\left[f\left(Z_{T}\right)<B_{T}\right]=P\left[Z_{T}<f^{-1}\left(B_{T}\right)\right]
\end{aligned}
$$

Now, we can get the Default Distance (abbr. DD) of maturing bonds on the basis of KMV's formula.

$$
D D=\frac{V_{T}-B_{T}}{\sigma_{V}}=-f^{-1}\left(B_{T}\right)
$$

Where $\boldsymbol{B}_{T}$ is the principal and interest of maturing bonds; $\sigma_{V}$ is the volatility of the local revenue

Further more, we find that the local revenue follows the probability distribution of Geometric Brownian motion for it could satisfy the Markov random process.

Expressed by the general Wiener process:

$$
\frac{d V_{t}}{V_{t}}=\mu d t+\sigma_{t} d z_{t}, t>0,
$$

Where $\sigma_{t}$ is the volatility rate of the local revenue at $t$ time; $\mu_{t}$ is the mean of growth rate at $t$ time; $d z_{t}$ is the increment of Wiener Process $\left(d z_{t}=\varepsilon \sqrt{d t}, \varepsilon \sim N(0,1)\right)$.

On the formula 4 , the local revenue at $t>0$ can be defined as:

$$
V_{t}=V_{0} \exp \left\{\left(\mu-\frac{1}{2} \sigma^{2}\right) t+\sigma \sqrt{t} Z_{t}\right\}
$$

Where $Z_{t} \sim N(0,1)$. So the local revenue is a lognormal distribution.

According to Ito Lemma:

$$
d f=\left(\frac{d f}{d V_{t}} \mu V_{t}+\frac{1}{2} \frac{d^{2} f}{d V_{t}^{2}} \sigma^{2} V_{t}^{2}\right) d t+\frac{d f}{d V_{t}} \sigma V_{t} d z
$$

Integrating the above equation, thus

$$
\begin{aligned}
& f\left(V_{T}\right)-f\left(V_{o}\right) \\
= & \int_{0}^{T}\left(\frac{d f}{d V_{t}} \mu V_{t}+\frac{1}{2} \frac{d^{2} f}{d V_{t}^{2}} \sigma^{2} V_{t}^{2}\right) d t+\int_{0}^{T} \frac{d f}{d V_{t}} \sigma V_{t} d z
\end{aligned}
$$

Set $f\left(V_{t}\right)=\ln V_{t}$, then $\frac{d f}{d V_{t}}=\frac{1}{V_{t}}, \frac{d^{2} f}{d V_{t}^{2}}=-\frac{1}{V_{t}^{2}}$

Hence, it can derived the following formula

$$
\ln V_{T}=\ln V_{0}+\left(\mu-\frac{\sigma^{2}}{2}\right) T+\sigma \sqrt{T} \varepsilon
$$

Now, we can get the expectation (mean) and variance of logarithmic local revenue at $\mathrm{T}$ time.

$$
\begin{gathered}
E\left(\ln V_{T}\right)=\ln V_{0}+\mu T-\frac{1}{2} \sigma^{2} T \\
\operatorname{Var}\left(\ln V_{T}\right)=\sigma^{2} T
\end{gathered}
$$

Based on the KMV, we supposed the change of revenue is a normal distribution. Then the local revenue is a lognormal distribution. So, we got the Expected Default Frequency (EDF) of local bonds:

$$
\begin{aligned}
p & =P\left[V_{T}<B_{T}\right]=P\left[\ln V_{T}<\ln B_{T}\right] \\
& =N\left(\frac{\ln B_{T}-\ln V_{T}-\mu T+\frac{1}{2} \sigma^{2} T}{\sigma \sqrt{T}}\right)
\end{aligned}
$$

The distance to default is:

$$
D D=\frac{\ln V-\ln B_{T}+\mu T-\frac{1}{2} \sigma^{2} T}{\sigma \sqrt{T}}
$$

Correspondingly the EDF is

$$
p=N(-D D)=1-N(D D)
$$

It's clearly that we can calculate default frequency directly after adjusting distance to default from raw data to logarithm.

Finally, we get the Expected Loss (EL).

$$
\begin{aligned}
E L= & B_{T} e^{-\mu T} N\left(\frac{\ln B_{T}-\ln V-\mu T+\frac{1}{2} \sigma^{2} T}{\sigma \sqrt{T}}\right) \\
& -V N\left(\frac{\ln B_{T}-\ln V-\mu T-\frac{1}{2} \sigma^{2} T}{\sigma \sqrt{T}}\right)
\end{aligned}
$$

Something need to be noted in original KMV is that the expected default frequency is not equal to the empirical value of default frequency for it's not sure that the company assets is a normal distribution and the complexity of default. So KMV Co., Ltd fits the relationship between distance to default and Expected Default Frequency to a smooth curve to determine the value of EDF ultimately grounded in a database containned a large number of historical corporate defaults information when the model is applied. But in China we can get the expected default frequency only because we didn't have such a database. This is a practical barrier that we couldn't settle in a short time.

\section{Model Evaluation and Analysis}


$\mathrm{KMV}$ is a credit risk measurement model constructed by the famous KMV Co., Ltd based on the Option Pricing Theory of Black-Scholes and Merton which fast becoming one of the most popular credit risk models in international finance.

Early success cases of KMV Co., Ltd include IBM, MCI WorldCom and Bank of Thailand, etc. When around in financial crisis there is many more success cases listed on its website. The most typical cases such as WCI Communities Inc, Visteon Corp, Georgia Gulf Corp, Chemtura Corporation, Nortel Networks Inc, Verasun Energy Group, etc. which received the warning from KMV Co., Ltd about half year before that indicated its strong ability to predict default risk.

However, there are some intrinsic flaws in the KMV model as others too which concentrated these areas, such as its not considering the market risk, the EDF is a Estimated value calculated on the basis of lots of historical data that the accuracy depends on the amount of data, it ignoring the changes in corporate credit rating, and without considering the moral hazard Under Asymmetric Information, etc. But objectively, this is just the necessary improve of the model in future.
To apply the model in this paper, we propose that the key issue of accuracy is to determine the probability distribution form of local revenue.

KMV model's idea originated from Black-Scholes Option Pricing Model in which the asset value is supposed to be a lognormal distribution.

$$
E=V_{a} N\left(d_{1}\right)-B e^{-r T} N\left(d_{2}\right)
$$

Although the return-on-assets is supposed to be a normal or lognormal distribution in general financial analysis, many economists and statisticians question the classic hypothesis-normal distribution-with theoretical and empirical research. From early Mandelbrot (1963, 1967) and Fama (1965) to Hsieh (1991) and Anderson (1996), they hold that the distribution of return-on-assets has distinct characteristics of leptokurtic and fat-tail with skewness in general rather than a normal distribution obviously.

We found that the local revenue is not a lognormal distribution completely but a fat-tail distribution after got its true probability distribution by Matlab software based on Beijing annual data of revenues.

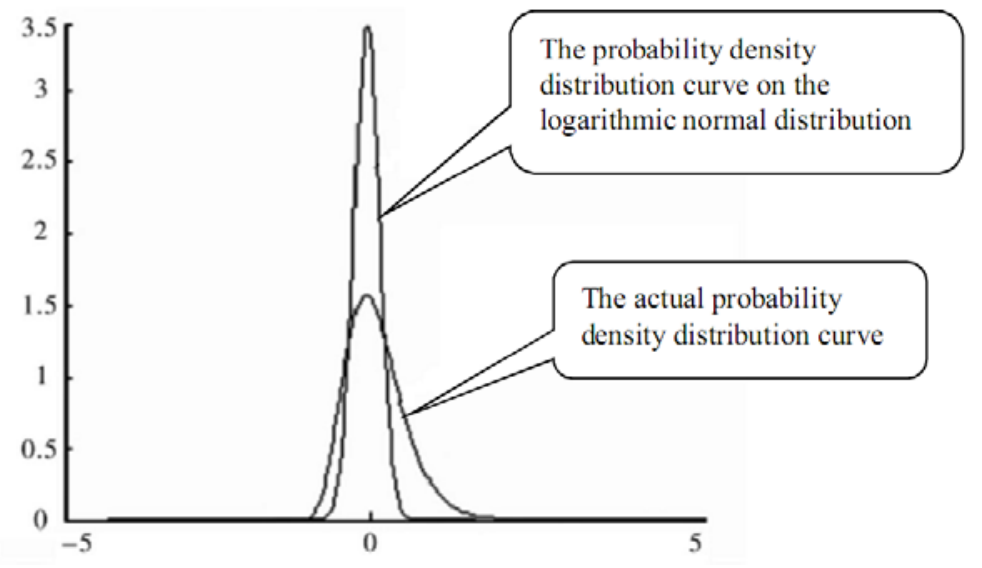

Figure 2. The probability distribution diagram of Beijing revenue)

Furthermore, we test the normal distribution hypothesis at the $95 \%$ confidence level on the basis of revised annual and monthly revenue data from 1990 respectively and get the Kurtosis and Skewness.

Annual data: $\mathrm{P}=0.996, \mathrm{~K}=-1.079, \mathrm{SK}=0.1468$

Monthly data: $\mathrm{P}=0.260, \mathrm{~K}=0.3907, \mathrm{SK}=-0.8668$.
Test results showed that the characteristics of leptokurtic and fat-tail significant more while the feature of normal distribution weakened. But in the view of application, we still assume the revenue is a lognormal distribution in practice becase there is no precise description yet in theories and its accuracy is uncertain.

Table 1. The prediction of safe bonds volume in 2009 ( $¥$ billion)

\begin{tabular}{|c|c|c|c|c|c|c|c|c|c|}
\hline Province & Beijing & Xinjiang & Shanxi & Anhui & Henan & Sichuan & Tianjian & Chongqing & Liaoning \\
\hline Forecast Revenue & 192 & 25 & 141.5 & 142.6 & 108 & 113 & 113.4 & 99.2 & 152 \\
\hline Payable Revenue & 76.8 & 10 & 56.6 & 57 & 43.2 & 45.2 & 45.4 & 39.7 & 60.8 \\
\hline Safe bonds volume & 38.4 & 5 & 28.3 & 28.5 & 21.6 & 22.6 & 22.7 & 19.8 & 30.4 \\
\hline The proportion of forecast GDP & $2.45 \%$ & $1.10 \%$ & $4.29 \%$ & $2.86 \%$ & $1.08 \%$ & $1.63 \%$ & $3.13 \%$ & $3.45 \%$ & $2.03 \%$ \\
\hline Actual bonds volume & 5.6 & 5.5 & 5.3 & 7.7 & 8.8 & 18 & 2.6 & 5.8 & 5.6 \\
\hline Coupon rate & $1.67 \%$ & $\begin{array}{l}1.61 \% \\
1.79 \%\end{array}$ & $1.76 \%$ & $\begin{array}{l}1.60 \% \\
1.72 \%\end{array}$ & $\begin{array}{l}1.63 \% \\
1.67 \% \\
\end{array}$ & $\begin{array}{l}1.65 \% \\
1.71 \%\end{array}$ & $1.78 \%$ & $1.70 \%$ & $\begin{array}{l}1.75 \% \\
1.79 \% \\
\end{array}$ \\
\hline
\end{tabular}

Note: 1 . The two numbers in the line Coupon rate indicate the bond issueing is divided into two parts.

2. Xinjiang is a particular case under the China's Policies towards Ethnic Minorities that the central government will appropriate financial subsidy to compensate its fiscal gap.

\section{The Prediction of Bonds Volume}

In consideration of 2009 is the first year issuing largescale local government bonds in China, upon the above model we take 2009 as an example when some provinces issued quasi-local bonds to forecast their revenues in 2009 
by ARIMA model after a comprehensive analysis of their structure and composition of financial revenue and expenditure to verify the validity of the model. So, we set the $40 \%$ of local revenue is the payable amount and suppose the the time period of default probability is one year. Then we determine the default probability $0.5 \%$ as the prerequisites when issued bonds referenced to the U.S. real. So, we can calculate the safe local bonds volume finally. The corresponding results as shown in Table 1.

We find that based on the above data, the forecast revenue is reasonable in that it consistent to the actual revenue in 2009 basically. In addition, the proportion of safe bonds volume to forecast revenue is under $20 \%$ and it to GDP is under $5 \%$ too on the premise of default probability $0.5 \%$. All in all, based on these analyses, the safe bonds volume calculated above of those provinces is rational. However, due to the serious covert liabilities of local government that we couldn't grasped integrally, the predicted results did not consider the covert liabilities which just the minefield.

\section{Conclusion and Discussion}

1. Although the local government bonds is considered as Quasi-gilt-edged bonds in the West, its inherent risk shouldn't be discounted. The central government needs to amend Budget Law in which Empower the right of issuing local bonds to local government and Adjust the budget period of 3-5 years cycle in this project to improve the capital efficiency.

2. The regulatory framework of credit rating, information disclosure and bond insurance, etc. should to establish to hasten the local government bonds mark.

3. The certain difference between the true and theoretical distribution of revenue affects the forecast accuracy to some extent. However, we should base on comprehensive qualitative and quantitative point of view to make predictions and judgments in applying for there is no accurate deptic in theorists yet.

It's a newborn thing that the local government bonds to our capital market which needs time to accept by investors and market. While we must recognize it's a certainty that the local government bonds will play an active role in promoting locals prosperity and development. From the view of normalizing the local debt management, marketoriented mechanism should be introduced in the field of local bonds in which the intermediate agencies related to law, accounting, credit rating, insurance, etc. played positive roles. In addition, hasten the pace of marketoriented interest rate reform under an integrated management framework on government debt management, namely scale control of debt, risk warning, debt budget and approve, disclosure of debt information, etc. to scientifically guide the development of local bonds market healthy and better serve local economic development.

\section{Acknowledgements}

The authors would like to thank the editor and anonymous referees for their input and direction, which substantially improved this paper. This work was partly supported by the Soft Science Research of Shanxi province (2013041014-02).

\section{References}

[1] Andersen T G. Return volatility and trading volume: An information flow interpretation of stochastic volatility[J]. The Journal of Finance, 1996, 51 (1): 169-204.

[2] Ang A, Longstaff F A. Systemic sovereign credit risk: Lessons from the US and Europe[J]. Journal of Monetary Economics, 2013, 60(5): 493-510.

[3] Black F, Scholes M. The pricing of options and corporate liabilities[J]. The journal of political economy, 1973, 81(3): 637654.

[4] Daniels K, Diro Ejara D, Vijayakumar J. Debt Maturity, Credit Risk, and Information Asymmetry: The Case of Municipal Bonds[J]. Financial Review, 2010, 45(3): 603-626.

[5] Downing C, Zhang F. Trading activity and price volatility in the municipal bond market[J]. The Journal of Finance, 2004, 59 (2): 899-931.

[6] Fama E F. Portfolio analysis in a stable Paretian market[J]. Management science, 1965, 11 (3): 404-419.

[7] Han L, Mou H, Wang Z, The Strategies of Risk Identification and Control On Municipal Bonds[J], 2005 (3):58-66 (in Chinese).

[8] Han L, Zheng C, Luo W, Wang Z, A Study of Credit Risk and Issue Volume of Municipal Bonds in China[J], Journal of Finance, 2003 (2):85-94 (in Chinese).

[9] Hong G, Warga A. An empirical study of bond market transactions[J]. Financial Analysts Journal, 2000, 56: 32-46.

[10] Hsieh D A. Chaos and nonlinear dynamics: application to financial markets[J]. The journal of finance, 1991, 46 (5): 18391877.

[11] Jarrow R A, Lando D, Turnbull S M. A Markov model for the term structure of credit risk spreads[J]. Review of financial studies, 1997, 10 (2): 481-523.

[12] Jordan B D. On the Relative Yields of Taxable and Municipal Bonds: A Theory of the Tax Structure of Interest Rates[J]. The Journal of Fixed Income, 2012, 22(1): 79-87.

[13] Kidwell D S, Trzcinka C A. Municipal bond pricing and the New York City fiscal crisis[J]. The Journal of Finance, 1982, 37 (5): 1239-1246.

[14] Leeper E M, Walker T B, Yang S C S. Fiscal foresight and information flows[J]. Econometrica, 2013, 81(3): 1115-1145.

[15] Mandelbrot B. The variation of certain speculative prices[J]. Journal of Business, 1963,36(4): 394-419

[16] Mandelbrot B. The variation of some other speculative prices[J]. Journal of Business, 1967,40(4) :393-413.

[17] McConnell M W, Picker R C. When cities go broke: a conceptual introduction to municipal bankruptcy[J]. The University of Chicago Law Review, 1993: 425-495.

[18] Merton R C. An intertemporal capital asset pricing model[J]. Econometrica: Journal of the Econometric Society, 1973, 41(5): 867-887.

[19] Merton R C. On the pricing of corporate debt: The risk structure of interest rates[J]. The Journal of Finance, 1974, 29 (2): 449-470.

[20] Milgrom P R, Weber R J. A theory of auctions and competitive bidding $[\mathrm{J}]$. Econometrica: Journal of the Econometric Society, 1982, 50(5): 1089-1122.

[21] Nanda V, Singh R. Bond insurance: What is special about munis?[J]. The Journal of Finance, 2004, 59 (5): 2253-2280.

[22] Nguyen T. The Basics of High Yield Municipal Bonds[J]. Investing in the High Yield Municipal Market: How to Profit from the Current Municipal Credit Crisis and Earn Attractive TaxExempt Interest Income, 2012: 1-13.

[23] Schultz P. The market for new issues of municipal bonds: The roles of transparency and limited access to retail investors[J]. Journal of Financial Economics, 2012, 106(3): 492-512.

[24] Shneyerov A. An empirical study of auction revenue rankings: the case of municipal bonds[J]. The RAND Journal of Economics, 2006, 37 (4): 1005-1022.

[25] Yawitz J B. Risk premia on municipal bonds[J]. Journal of Financial and Quantitative Analysis, 1978, 13 (03): 475-485. 